\title{
Antiinflammatory activity of Flavonoids isolated from Rhus Mysorensis
}

\author{
Ganji Renuka rani* ${ }^{1,2}$, Singara Charya $\mathrm{MA}^{2}$, M. Viswanadham ${ }^{1}$, \\ Murali Krishna Thupurani ${ }^{3}$ \\ ${ }^{1 .}$ Department of Environmental Sciences, JNTU, Hyderabad \\ ${ }^{2}$. Department of Microbiology, Kakatiya University, Warangal, India. \\ ${ }^{3}$. Department of Biotechnology, Chaitanya PG. College (Autonomous), Kakatiya University, Warangal, India \\ *Corresponding author \\ e renukarani@yahoo.co.in \\ +919908760658
}

\begin{abstract}
Inflammation is part of the complex biological response of body tissues to harmful stimuli, such as pathogens, damaged cells, or irritants, and is a protective response involving immune cells, blood vessels, and molecular mediators. Medicinal plants have been long lastingly recognized as potential sources of natural drugs. The present study was framed to evaluate anti-inflammatory activity of the compounds isolated from Rhus mysorensis. The study was carried out using in vitro and in vivo methods. In vitro anti inflammatory activity of isolated compounds was screened using egg albumin. The inhibition of protein denaturation was

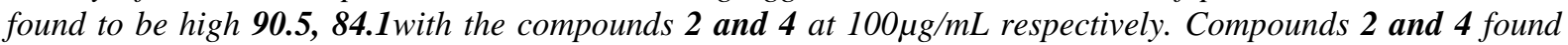
active in reducing the paw volume $0.88 \pm 0.26,1.35 \pm 0.11$ at fourth hour of treatment.
\end{abstract}

Keywords: egg albumin, Inflammation, paw volume, Rhus mysorensis

\section{Introduction}

Inflammation is part of the complex biological response of body tissues to harmful stimuli, such as pathogens, damaged cells, or irritants, and is a protective response involving immune cells, blood vessels, and molecular mediators ${ }^{[1]}$. In the modern concept Inflammation is associated with common symptoms generally are swelling, loss of function and heat ${ }^{[2]}$. Acute transient phase, delayed sub acute phase and chronic proliferate phase are the three different phases which are usually categorized in the reactions of inflammation ${ }^{[3]}$. In Ayurveda and Allopathic, antagonistic mediators are commonly used to prevent the inflammatory processes. The anti-inflammatory drugs which are most widely used as modern drugs and are proven as potential inhibitors especially of that produces prostaglandins is cyclooxygenase COX pathway ( arachidonic acid metabolism). In Indian Ayurvedic system Boswellia serrata Roxb has been extensively and widely used medicine as the source of potential inflammatory drugs ${ }^{[4-7] .}$ Plant derivatives viz., phenolic compounds and flavonoids are observed with anti-inflammatory activity regulates the levels of various inflammatory cytokines or mediators (IL-1, IL-6, IL-10, TNF- $\alpha$, NF- $\mathrm{KB}, \mathrm{NO}$, iNOS and COX-2) have been reported by number of studies on plant derived compounds ${ }^{[8]}$. Medicinal plants have been long lastingly recognized as potential sources of natural drugs ${ }^{[9]}$. In traditional medicine for the treatment of inflammatory diseases several medicinal plants are widely used. In the treatment of inflammatory disorders many of these medicinal plants have been already established preliminary and clinical evidence. Isolation and characterization of a number of anti-inflammatory compounds structurally as well as pharmacologically have been perpetuating ${ }^{[10]}$. Among such valuable and therapeutically immense important medicinal plants, it is known that Rhus mysorensis belongs to Anacardeaceae also exhibits pharmacological properties. Thus, in context to the hazardous effects of synthetic anti inflammatory drugs, the present study was framed to evaluate the anti-inflammatory activity of four flavonoids which were previously isolated from hydroalcoholic fractions of leaf and rhizomes of Rhus mysorensis (The data of isolation is yet to be published). The evaluation was carried in two different ways initially these hydroalcholic extracts were investigated for in vitro anti-inflammatory activities by inhibition of egg albumin denaturation process and based on these results we have followed in vivo anti-inflammatory activities.

\subsection{Anti-inflammatory activity}

\section{Material and Methods}

\subsubsection{Preliminary studies on anti-Inflammatory activities of compounds isolated from Rhus mysorencies}

Preliminary studies on anti-inflammatory activities of the isolated from Rhus mysorencies leaves and roots were determined by the described method ${ }^{[11]}$. About of $5 \mathrm{~mL}$ reaction mixture includes of $0.2 \mathrm{~mL}$ of egg albumin, $2.8 \mathrm{~mL}$ of phosphate buffered saline (PBS, pH 6.4) add $2 \mathrm{~mL}$ of isolated compounds at 10, 20, 40, 60, 
80 and $100 \mu \mathrm{g} / \mathrm{mL}$. Double-distilled water with same volume used as control. The mixtures were incubated at $(37 \pm 2){ }^{0} \mathrm{C}$ in BOD incubator for about $15 \mathrm{~min}$ and followed by heating at $70{ }^{\circ} \mathrm{C}$ for $5 \mathrm{~min}$. After attaining room temperature, absorbance was measured at $660 \mathrm{~nm}$ using vehicle as blank and viscosity was determined by using Ostwald viscometer. Ibuprofen at the final concentration of $(10,20,40,60,80,100 \mu \mathrm{g} / \mathrm{mL})$ was used as reference drug. The inhibition percentage of protein denaturation was calculated using the following formula:

$$
\% \text { inhibition }=100 \times(\mathrm{Vt} / \mathrm{Vc}-1)
$$

Where, $\mathrm{Vt}=$ absorbance of test sample, $\mathrm{Vc}=$ absorbance of control.

\subsubsection{In vivo anti-inflammatory activity} Animals

Albino rats of Wistar strain, of male sex, weighing 150 - $250 \mathrm{~g}$ were purchased from National Institute of Nutrition, Hyderabad, India and housed under standard environmental conditions (temperature: $24 \pm 1$ o C, light / dark cycle: 10/14 h). The rats were fed with standard pellet diet (Amrut laboratory animal feed, Maharashtra, India) and water ad libitum. Animals were acclimatized to laboratory conditions at least 1 week before conducting the experiments according to the guide lines of CPCSEA - New Delhi, (Registration No. 915/ac/05/CPCSEA).

\section{Activity}

The isolated compounds were assessed for their anti-inflammatory activity using carrageenan-induced hind paw edema method. The rat paw edema was induced by subcutaneous injection of $0.1 \mathrm{ml}$ of $1 \%$ freshly prepared saline solution of carrageenan into the right hind paw of rats ${ }^{[12]}$. The standard drug Ibuprofen (100 $\mu \mathrm{g} / \mathrm{kg} / \mathrm{p} . \mathrm{o}$ ) was given orally as a positive control. The control group was administered orally with $0.9 \%$ of 0.1 $\mathrm{ml}$ of saline solution only. The test groups were administered orally with the isolated compounds at the equimolar dosage of the standard drug, $1 \mathrm{~h}$ before the administration of carrageenan. The paw volumes were measured using plethysmometer at interval of $24 \mathrm{~h}$.

\section{Result and discussion}

In accordance to the data of the present investigation the anti-inflammatory activity of compounds isolated form Rhus mysorensis was found to be in concentrated dependent manner. In vitro anti inflammatory activity of isolated compounds were screened using egg albumin. The protein denaturation was found to be compounds concentration dependent. Among the compounds $\mathbf{2}$ and $\mathbf{4}$ are found highly active at all concentrations tested and noticed highest inhibition percentages 90.5, 84.1 at $100 \mu \mathrm{g} / \mathrm{mL}$ respectively. The activity of these compounds is very much comparable with the known standard Ibuprofen. Results are shown in table 1.

All the isolated compounds showed in vivo anti-inflammatory activity by significant inhibition of edema (Table 2). The in vivo anti-inflammatory activity of isolated compounds is quite different compared to that from in vitro activity. Accordance to present investigation results, we observed that compounds which are active in vitro exhibited moderate in vivio activity. The reduction in the paw volume and subsequent antiinflammatory activity by the compounds was noticed in fourth and fifth hour and slightly increased in sixth hour. Compounds 2 and 4 found active by reducing paw volume $0.88 \pm 0.26,1.35 \pm 0.11$ at fourth hour of treatment and comparable with the values of the positive control Ibuprofen.

Generally inflammatory diseases are treated using traditional remedies. Now-a-days, scientists are paying large amounts of hard work to evaluate the potential herbal remedies as novel bioactive compounds that leads for the development of anti inflammatory drugs ${ }^{[13]}$. The common mechanism involved in the reduction of edema in the rat paw is due to the release of histamine and serotonin, prostaglandins, protease and lysosome ${ }^{[14]}$. The anti-inflammatory of various flavonoid derivatives were previously reported using various models such as human neutrophil functions, eicosanoid release, TNF- $\alpha$ production, air-pouch ${ }^{[15-17]}$. In the current study we have evaluated the anti-inflammatory activity of four flavonoids which we were isolated from the Rhus mysorensis root and stem (Data was not shown). Compounds screened in the current study have been shown to possess antiinflammatory activity by the inhibition of histamine induced vascular permeability and reverse passive Arthus reaction ${ }^{[18-19]}$. 
Table 1 In vitro Anti-inflammatory activity of compounds isolated from Rhus mysorensis plant extract

\begin{tabular}{|l|c|c|c|c|c|c|}
\hline \multicolumn{1}{|c|}{ compounds } & $\mathbf{1 0} \mathbf{\mu g} / \mathbf{m L}$ & $\mathbf{2 0} \mathbf{\mu g} / \mathbf{m L}$ & $\mathbf{4 0} \mathbf{\mu g} / \mathbf{m L}$ & $\mathbf{6 0} \mathbf{\mu g} / \mathbf{m L}$ & $\mathbf{8 0} \mathbf{\mu g} / \mathbf{m L}$ & $\mathbf{1 0 0} \mathbf{\mu g} / \mathbf{m L}$ \\
\hline Control (-) & -- & -- & -- & -- & - & -- \\
\hline Ibuprofen & $68.3 \pm 0.1$ & $75.8 \pm 1.2$ & $82.1 \pm 1.7$ & $88.7 \pm 1.2$ & $93.6 \pm 1.6$ & $98.3 \pm 1.1$ \\
\hline Compound 1 & $48.1 \pm 1.0$ & $52.3 \pm 1.5$ & $56.0 \pm 1.4$ & $62.1 \pm 1.2$ & $66.1 \pm 1.1^{\mathrm{b}}$ & $70.3 \pm 1.2^{\mathrm{b}}$ \\
\hline Compound 2 & $57.1 \pm 1.6$ & $62.1 \pm 1.1$ & $69.3 \pm 2.0^{\mathrm{b}}$ & $78.2 \pm 1.2^{\mathrm{a}}$ & $83.1 \pm 1.1^{\mathrm{a}}$ & $90.5 \pm 1.4^{\mathrm{a}}$ \\
\hline Compound 3 & $50.5 . \pm 1.1$ & $54.4 \pm 1.5$ & $59.0 \pm 1.0^{\mathrm{b}}$ & $66.1 \pm 1.1^{\mathrm{a}}$ & $70.6 \pm 1.8^{\mathrm{a}}$ & $76.2 \pm 1.2^{\mathrm{a}}$ \\
\hline Compound 4 & $54.4 \pm 1.1$ & $59.0 \pm 1.3$ & $64.5 \pm 1.0^{\mathrm{b}}$ & $71.1 \pm 1.1^{\mathrm{a}}$ & $77.3 \pm 1.2^{\mathrm{a}}$ & $84.1 \pm 1.0^{\mathrm{a}}$ \\
\hline
\end{tabular}

Compound 1; 2-(3,4-dihydroxyphenyl)-3,5,7-trihydroxy-4H-chromen-4-one, Compound 2; 2-(3,4dihydroxyphenyl)-hydroxy-4H-chromen-4-one, Compound 3; 2-(3,4-dihydroxyphenyl)-3,7-dihydroxy-4Hchromen-4-one, Compound 4; 5,6,7-trihydroxy-2-phenyl-4H-chromen-4-one

Values are expressed as Percentage \pm SD from six observations and Data is analyzed by one way ANOVA followed by Dunnett's ' $t$ ' test. aindicates $\mathrm{P}<0.001 \&{ }^{\mathrm{b}}$ indicates $\mathrm{P}<0.01$. Concentration of the compounds in $\mu \mathrm{g} / \mathrm{mL}$.

Table 2 In vivo Anti-inflammatory activity of compounds isolated from Rhus mysorensis plant extract

\begin{tabular}{|c|c|c|c|c|c|c|}
\hline \multirow{2}{*}{$\begin{array}{l}\text { Compounds } \\
\mu \mathrm{g} / \mathrm{mL}\end{array}$} & \multicolumn{6}{|c|}{ Swelling (AI \%) } \\
\hline & $1 \mathrm{hr}$ & $2 \mathrm{hr}$ & $3 \mathrm{hr}$ & $4 \mathrm{hr}$ & $5 \mathrm{hr}$ & $6 \mathrm{hr}$ \\
\hline Control (-) & $1.25 \pm 0.039$ & $1.40 \pm 0.011$ & $1.65 \pm 0.020$ & $1.90 \pm 0.011$ & $2.78 \pm 0.015$ & $3.91 \pm 0.011$ \\
\hline Ibuprofen & $\begin{array}{l}0.07 \pm 0.019 \\
(94.4)\end{array}$ & $\begin{array}{l}0.08 \pm 0.021 \\
(94.2)\end{array}$ & $\begin{array}{l}0.06 \pm 0.017 \\
(93.6)\end{array}$ & $\begin{array}{l}0.10 \pm 0.021 \\
(94.7)^{\mathrm{b}}\end{array}$ & $\begin{array}{l}0.11 \pm 0.026 \\
(96.0)^{\mathrm{a}}\end{array}$ & $\begin{array}{l}0.11 \pm 0.025 \\
(97.1)\end{array}$ \\
\hline Compound 1 & $3.59 \pm 0.10(28.1)$ & $3.32 \pm 0.08(33.7)$ & $\begin{array}{l}3.09 \pm 0.012 \\
(39.0)\end{array}$ & $2.81 \pm 0.20(48.9)$ & $2.75 \pm 0.11(55.0)$ & $2.89 \pm 0.29(50.1)$ \\
\hline Compound 2 & $1.78 \pm 0.10(42.1)$ & $1.50 \pm 0.03(53.6)$ & $1.33 \pm 0.18(63.3)$ & $\begin{array}{l}0.88 \pm 0.26(76.8) \\
\text { a }\end{array}$ & $\begin{array}{l}0.69 \pm 0.07(81.5) \\
\text { a }\end{array}$ & $\begin{array}{l}0.81 \pm 0.011 \\
(72.2)\end{array}$ \\
\hline Compound 3 & $2.68 \pm 0.12(32.4)$ & $2.45 \pm 0.06(39.7)$ & $2.23 \pm 0.19(45.4)$ & $\begin{array}{l}2.09 \pm 0.03 \\
(52.1)^{\mathrm{b}}\end{array}$ & $1.85 \pm 0.14(66.1)$ & $\begin{array}{l}1.95 \pm 0.004 \\
(60.7)\end{array}$ \\
\hline Compound 4 & $2.10 \pm 0.11(37.2)$ & $1.77 \pm 0.09$ (41.9) & $1.50 \pm 0.23(49.6)$ & $1.35 \pm 0.11(58.4)$ & $1.11 \pm 0.10(65.9)^{\mathrm{a}}$ & $1.42 \pm 0.19(53.2)$ \\
\hline
\end{tabular}

Compound 1; 2-(3,4-dihydroxyphenyl)-3,5,7-trihydroxy-4H-chromen-4-one, Compound 2; 2-(3,4-

dihydroxyphenyl)-hydroxy-4H-chromen-4-one Compound 3; 2-(3,4-dihydroxyphenyl)-3,7-dihydroxy-4H-

chromen-4-one, Compound 4; 5,6,7-trihydroxy-2-phenyl-4H-chromen-4-one

Values are expressed as Percentage \pm SD from six observations and Data is analyzed by one way ANOVA followed by Dunnett's ' $t$ ' test. ${ }^{a}$ indicates $\mathrm{P}<0.001 \&{ }^{\mathrm{b}}$ indicates $\mathrm{P}<0.01$. Concentration of the compounds in $\mu \mathrm{g} / \mathrm{mL}$.

\section{Conclusion}

Basing on our studies, we conclude that the compounds isolated from the Rhus mysorensis exhibit the antiinflammatory activity. However, the further studies are required to use these compounds as anti-inflammatory agents.

\section{Acknowledgement}

The authors sincerely thank to the Dr. A. Thirupatiah, Assistant Professor, Natural Products Laboratory, Chaitanya Degree and PG College (Autonomous), for his valuable suggestions during extraction and performing anti-inflammatory activity.

\section{References}

[1]. Neville A Punchard, Cliff J Whelan, ian adcock J, The journal of inflammation Inflamm (lond), $2004 ; 1: 1$.

[2]. S Chaturvedi, S Drabu Sharma, Anti- Inflammatory and analgesic activity of Tamarix Gallica, International Journal of Pharmacy and Pharmaceutical Sciences, 4(), 2012, 0975-1491.

[3]. Victor Kuete Medicinal Plant Research In Africa (Elsevier)2013.

[4]. U Dahmen, O Guyl Dirsch, LM Fan, K Li shen, CE Broelsch, Boswellic acid a potent anti inflammatory drug, inhibits rejection to the same extent as high dose steroids, Transplant Proc,33(1-2),2001, 539-541.

[5]. H P Ammon, Boswellic acids ( components of frankin cense ) as the active principle in treatment of chronic inflammation diseases, Wien Med Wochemschr, 152(15-16), 2002, 373-378.

[6]. M K Menon, and A Kar, Analgesic and anti-psycho pharmacological effects of the gum resin of Boswellia serrata, Planta Med 19(4), 1971. 333-341.

[7]. N Kimmathkar, V Thawani, L Hingrani, R Khiyani, Efficacy and tolerability of Boswellia serrata extracts in treatment of Osteoarthritis of knee a randomized double blind placelo controlled trail, Phytomedicine, 10(1),2003, 3-7.

[8]. T Debnath, DH Kim,OL Beong, Natural Products as a source of Anti-inflammatory Agents Associated with Inflammatory Bowel Disease, Molecules, 18(6),2013, 7253-7270.

[9]. C Veeresham, Natural Products Derived From Plants As A Source Of Drugs, Journal of Advanced Pharma Technol Res 3(4), 2012, 200-201.

[10]. M Sunil and C Hoskinsdrug, Development: Lessons from Nature, Biomed Rep, 6(6), 2017, 612-614. 
[11]. S Chandra, C Priyanka, D Protapaditya, S Bhattacharya, Evaluation of in vitro anti-inflammatory activity of coffee against the denaturation of protein, Asian Pacific Journal of Tropical Biomedicine, 2(1), 2012,178-180.

[12]. CA Winter, EA Risley, GW Nuss, Carrageenin induced edema in hind paw of the rat as assay for anti-inflammatory drugs, Exp Bio Med,111(1),1962, 544-547.

[13]. TS Ismail, S Gopalakrishnan, VH Begum, V Elango, Anti-inflammatory activity of Salacia oblonga Wall. and Azima tetracantha Lam, J. Ethnopharmacol, 56 (2), 1997, 145-152.

[14]. O Olajide, JM Makinde, SO Awe, Effects of the aqueous extract of Bridelia ferruginea stem bark on carrageenan-induced oedema and granuloma tissue formation in rats and mice, J. Ethnopharmacol, 66 (1), 1999, 113-117.

[15]. LE Pelzer, T Guardia, AO Juarez, E Guerreiro, Acute and chronic antiinflammatory effects of plant flavonoids. Farmaco, 53 (6), 1998, 421-424.

[16]. F Herencia, LM Ferrandiz, A Ubeda, I Guillen, JN Dominguez, JE Charris, GM Lobo, MJ Al-caraz, Novel anti-inflammatory chalcone derivatives inhibit the induction of nitric oxide synthase and cyclooxygenase-2 in mouse peritoneal macrophages. FEBS Lett, 453(1-2), 1999, 129-134

[17]. R Corra, MA Pereira, D Buffon, L Dos Santos, V Cechinel Filho, AR Santos, RJ Nunes, Antinociceptive properties of chalcones. Structure- activity relationships, Arch. Pharm, 334(10), 2001, 332-334.

[18]. XC Tang, ZG Lin, W Cai, N Chen, L Shen, Antiinflammatory effect of 3-acetylaconitine.Acta Pharmacol. Sin. 5(2) 1984, 85-89.

[19]. R.G Naik, LS Kattice, SV Bhat, B Alreja, NJ Souza, RH Rupp, An anti-inflammatory cum immunomodulatory piperidinylbenzopyranone from Dysoxylum binectariferum: isolation, structure and total synthesis, Tetrahedron, 44 (7) 1988, 20812086 . 